\title{
SOMATOSTATIN ANALOGUES FOR THE TREATMENT OF NEUROENDOCRINE TUMOURS. DOSAGE FORMS AND ROUTES OF ADMINISTRATION (REVIEW)
}

\author{
ZOYA SHPRAKH ${ }^{\mathrm{a}, \mathrm{b}^{*}}$ \\ aN. N. Blokhin National Medical Research Center of Oncology (N. N. Blokhin NMRCO), 24 Kashirskoye Sh., Moscow, 115478, Russia, bI. M. Sechenov \\ First Moscow State Medical University (Sechenov University), 8-2 Trubetskaya St., Moscow, 119991, Russia \\ Email: z.shprakh@ronc.ru
}

Received: 06 Dec 2019, Revised and Accepted: 22 Jan 2020

\begin{abstract}
This review summarises information on drug products Somatostatin Analogues (SSAs), which are included in the algorithm of Neuroendocrine Tumors (NET) treatment. SSAs are the current standard for safe and effective management of NET symptoms and control of tumours growth and are administered in a range of dosage forms for parenteral administration, such as intramuscular, subcutaneous and implant. A search criterion was the therapy of NET with medicines from a group of SSAs. Literature survey has been done in a range of years 1990-2018 to make the review updated and comprehensive and to show the development of SSAs new pharmaceutical dosage forms to improve patient quality of life and side effects decrease. The sources were world-recognized journals. Keywords used as filters were NET, SSAs, octreotide, lanreotide, pasireotide, Somatostatin Receptors (SSTR), dosage form. The current review is created with an intended to focus on the advantage of SSAs modern dosage forms. Literature survey revealed that many studies were carried out to SSAs encapsulation into microspheres that changes the drug bioavailability and allows reducing the number of administration. Also, SSAs delivery systems in particular devices such as auto-injector have been created to control the continuous concentration of the drug and to provide safety guarantee. Besides, studies have been carried out to prepare SSAs formulations for oral administration to improve the quality of life of the NET patients. In this review, SSAs pharmaceutical dosage forms with improved pharmacokinetic and therapeutic characteristics and routes of administration are analyzed.
\end{abstract}

Keywords: Neuroendocrine tumours, Somatostatin analogues, Dosage form of prolonged-release, Oral administration

(C) 2020 The Authors. Published by Innovare Academic Sciences Pvt Ltd. This is an open access article under the CC BY license (http://creativecommons.org/licenses/by/4.0/) DOI: http://dx.doi.org/10.22159/ijap.2020v12i2.36558. Journal homepage: https://innovareacademics.in/journals/index.php/ijap

\section{INTRODUCTION}

Neuroendocrine Tumours (NET) are a rare disease which occurs in less than $1 \%$ of the population [1]. NET is characterised by the presence of secondary symptoms, which are caused by hypersecretion of metabolically active substances-biogenic amines and regulatory peptide hormones [2].

Somatostatin Analogues (SSAs) have a special place in the treatment of NET. Medicines of this class not arrest only clinical symptoms and reduce the level of tumour biochemical markers but also have antiproliferative activity [3-6]. These days SSAs are the current standard for safe and effective management of gastropancreatic NET symptoms [7-9]. These drugs are the treatment of choice for control of tumours growth in patients with inoperable NET $[10,11]$.

Natural somatostatin is synthesised in many tissues, including the central and peripheral nervous system, hypothalamus, pancreatic islet cells (D-cells), glandular and neuronal cells of the stomach and intestine [7, 12]. Somatostatin controls many physiological functions: neurotransmission, smooth muscles contractility, stomach and intestinal motor functions and nutrient absorption. It reduces the growth of neuroendocrine neoplasms, inhibiting proliferation and angiogenesis of tumour cells, as well as inducing apoptosis [13].

Somatostatin was first isolated in 1973 by French researchers but, despite the high biological activity, it never became a drug product. Natural somatostatin cannot be used as a drug due to its very short half-life in blood plasma (not more than $3 \mathrm{~min}$ ).

Already in 1974, the pharmaceutical company Sandoz GmbH, Germany, initiated a project to obtain long-acting synthetic analogues with a higher activity vs native somatostatin. Later, SSAs were created, which proved to be more resistant to enzymatic decomposition and possessed improved pharmacokinetic and therapeutic characteristics $[14,15]$.

To prepare this review search criterion was the therapy of NET with medicines from the group of SSAs. Literature survey has been done in a range of years 1990-2018 to make the review updated and comprehensive and to show the development of SSAs new pharmaceutical dosage forms to improve patient quality of life and side effects decrease. The sources were world-recognized journals. Keywords used as filter were NET, SSAs, octreotide, lanreotide, pasireotide, Somatostatin Receptors (SSTR), dosage form.

\section{Octreotide-SSA of the first generation}

The first and most studied SSA is octreotide (INN), which is characterised by more than $30 \mathrm{y}$ of practical active and safe use $[16,17]$.

Octreotide is the synthetic cyclic octapeptide. It has similar to somatostatin profile of pharmacological activity but is more biologically active due to significantly longer half-life (about $10 \mathrm{~min}$ ) [18]. The group of octreotide containing medicines includes immediate-release and long-acting dosage forms. Solutions for injections or infusions represent "short-acting" drugs, and dosage forms of prolonged action are lyophilised microspheres for suspension for intramuscular administration. It should be noted that short-acting and long-acting drug products do not show crossresistance and can be successfully replaced by each other [19].

Initially, octreotide was synthesised as a drug product of immediate release administered 2-3 times a day. Octreotide for injection is a transparent, colourless sterile solution of octreotide acetate for intravenous or subcutaneous administration with the concentration of 0.05 to $0.6 \mathrm{mg} / \mathrm{ml}$ in ampoules or $1 \mathrm{ml}$ bottles or multidose vials containing $5 \mathrm{ml}$ of $0.2 \mathrm{mg} / \mathrm{ml}$ or $1 \mathrm{mg} / \mathrm{ml}$ solution. The drug is also produced in pre-filled disposable syringes (trade name-Serakstal, Italfarmaco, Italy). Each ampoule of octreotide solution contains excipients: lactic acid, mannitol, sodium bicarbonate and water for injection. Lactic acid and sodium bicarbonate are added to produce a buffering solution with a $\mathrm{pH}$ of $4.2 \pm 0.3$. Multidose vials also include $5 \mathrm{mg}$ of phenol per $\mathrm{ml}$ as the preservative.

Octreotide solution is used in acute conditions, such as bleeding ulcer. It is not suitable for long-term treatment of NET due to the need for frequent injections (3-4 times a day). These days biotherapy of NET uses long-acting octreotide in the depot-forms (LAR), administering intramuscularly once per month [19]. 


\section{Octreotide depot-forms}

The most studied and widely used long-acting SSA is Sandostatin ${ }^{\circledR}$ LAR, Novartis Pharma AG, Switzerland [7]. It has advantages over short-acting octreotide due to the ability to maintain a continuous concentration of the drug in the body, which increases the symptomatic and antitumour effects.

Sandostatin ${ }^{\circledR}$ LAR is a powder for suspension for intramuscular injections. It contains octreotide, encapsulated and evenly distributed inside microspheres made of lactic and glycolic acids copolymer and D-(+)-glucose (PLGA D-(+) glucose). Encapsulation of octreotide into unique microspheres determines its pharmacokinetics profile so that the number of injections is reduced from 3 per day to 1 per month. The gradual slow release of octreotide occurs during biodegradation of the polymer, especially with its hydrolysis. The polymer has an average molecular mass of about $\sim 52 \mathrm{kDa}$, the average diameter of microspheres is approximately 50 microns. The bottle with the drug is accompanied by a compound solvent, in a pre-filled disposable syringe. When mixing lyophilised microspheres with solvent, the suspension is formed. The solvent contains sodium carboxymethyl cellulose, mannitol, poloxamer 188 and water for injection and is a transparent solution from colourless to light yellow or brown colour. Mannitol is added to the dosage form to improve suspending. The resuspending of the drug is carried out upon cooling and involves seven different stages, including a very delicate shaking to obtain a homogeneous suspension before administration. The disadvantages of the product include a complicated procedure of drug preparation for administration, extreme pain after intramuscular injection with a long thick needle and the prolonged duration of the dose due to the high viscosity of the suspension.

The new depot form of the octreotide for subcutaneous administration (Novartis Pharma AG, Switzerland) was developed using FluidCrystal ${ }^{\circledR}$ technology (Camurus AB, Lund, Sweden) to remove the above restrictions for Sandostatin ${ }^{\circledR}$ LAR. The name of the drug is Octreotide FluidCrystal ${ }^{\circledR}$ Product CAM2029. It is a readyto-use prolonged dosage form of octreotide, expected to be marketed in pre-filled syringes (product can be injected by patients independently with auto-injector). It is intended for subcutaneous injection through a thin needle (22-27 G). A biodegradable liquid crystal gel is formed at the site of injection by the administration of a small volume of liquid. The liquid-crystal phase formulation is a spontaneous process, which is the result of the lipids selfaggregation, which begins immediately after injection. Immediate start of gel formulation leads to the effective release of the active substance from depot matrix, providing rapid ("burst") initial release (without opening), follows by a slower and stable stage of the drug release.

Phase I and II comparative clinical trials of octreotide-depot subcutaneous administration and Sandostatin ${ }^{\circledR}$ LAR showed that the octreotide-depot injected subcutaneously, has a satisfactory safety profile. It is similar to that of the prolonged octreotide dosage form and corresponds to Sandostatin $\AA$ LAR in terms of the duration of the therapeutic effect. The clear advantages of octreotide-depot subcutaneous are five times higher bioavailability, which allows effective control of symptoms in patients with functioning NET, and convenience of drug application by patients and medical personnel [20-22].

The pharmaceutical company Endo Pharmaceuticals, Ireland, also attempted to create a prolonged-release dosage form of octreotide. This company has developed a pharmaceutical composition for subcutaneous administration as an implant. The drug is octreotide enclosed in a polyurethane/methacrylate hydrophilic polymer, releasing 30 to $800 \mu \mathrm{g}$ of active substance per day for six months in vivo. The hydrophilic polymer additionally contains the releasing agent Brij 35 (polyoxyethylene lauryl ether), polyoxyethylene (20) sorbitan trioleate, tween 20, tween 80, vitamin E TPGS and/or their mixtures. The dose of octreotide in the implant is from 40 to $120 \mu \mathrm{g}$ [23].

Phase II and III clinical trials have demonstrated the safety and efficacy of octreotide-implant in patients who previously used Sandostatin ${ }^{\circledR}$ LAR. Advanced studies have shown that biochemical parameters and safety profiles remain unchanged for more than 24 $\mathrm{w}[24,25]$.

\section{Lanreotide and its long-acting dosage forms}

Another SSA, actively used in clinical practice, is lanreotide. Lanreotide is a cyclic octapeptide containing D-tryptophan inside the ring, which stabilizes the molecule. N-end D-alanine increases the selectivity of the drug. Advanced researches have established that lanreotide provides 85 times higher antisecretory effect than that of native somatostatin [26].

The drug is used in two long-acting dosage forms-Somatuline ${ }^{\circledR}$ and Somatuline $\AA$ Autogel $®$ (Ipsen Pharma, France).

Somatuline ${ }^{\circledR}$ is a lyophilisate for suspension for intramuscular injection. Just as in Sandostatin $®$ LAR, in this dosage form lanreotide is enclosed in microspheres of the copolymer of lactic and glycolic acids. The gradual release of lanreotide from microspheres causes prolonged (up to 10-14 d) presence of the drug in the blood. At the same time, the pharmacological efficacy of the drug can be adjusted by changing the duration of time between injections: 7, 10 or $14 \mathrm{~d}$ [27]. The vial with lyophilisate is provided with the ampoule with solvent ( $0.8 \%$ mannitol solution) to disperse in it to form a suspension of the white or off-white colour.

Octreotide and lanreotide depot-forms obtained by microencapsulation have shown efficacy in the treatment of NET. But nowadays such dosage forms are considered first-generation drugs due to many of medical disadvantages: the need to dissolve before administration, the probability of step-like or even "burst" release of the active substance, the formation of acid (acidic) metabolites in the process of polymer degradation and possible degradation of peptide $[28,29]$. Technological process of these dosage forms is rather complicated and often requires the use of organic solvents, which are toxic [30].

Besides, intramuscular injections of these drugs are often painful; the need of administration of large volume leads to a limitation of the amount of a single drug administered and, therefore, leads to reducing the time between injections and consequently reducing patient's quality of life. All these factors required the development of a new dosage form of lanreotide with an improved pharmacokinetic profile and free of the above disadvantages.

In the process of such dosage form development, it was found that under certain conditions lanreotide in an aqueous solution forms a gel without the use of excipients or additional procedures [31-37]. At first, lanreotide as a cyclic octapeptide forms noncovalent dimers. They joined into filaments (fibres) stabilized by hydrogen bonds. Twenty-six filaments form a hollow nanotube of uniform diameter equal to $24 \mathrm{~nm}$. The structure of the soft gel depends on lanreotide concentration: at $10-15 \%$ nanotubes in the soft gel can be organized into a hexagonal crystal lattice. At higher lanreotide levels, the densely packed tube with nanotubes inside begins to form. Noncovalent hydrogen bonds between dimer subunits, hydrophobic interactions and $\pi-\pi$ staking of aromatic side chains inside threads stabilize nanotubes $[35,38]$.

Such interactions can be formed and exist in water and do not require the presence of any excipients. In vitro experiments have shown that the formation of such nanotubes is reversible: at low concentrations of lanreotide, nanotubes slowly "disassemble", releasing the active substance in a slow and controlled manner immediately after transfer to the diluted solution [39]. The drug product was called Somatuline ${ }^{\circledR}$ Autogel $®$.

It is recognized that in vivo Somatuline ${ }^{\circledR}$ Autogel $($ forms a depot at the site of injection when the dosage form interacts with physiological fluids. Lanreotide peptide properties regulate the release of the active substance. Likely it occurs due to passive diffusion of lanreotide from the depot into surrounding tissues with subsequent absorption into the blood [39].

Indeed, clinical trials of drug pharmacokinetics confirmed that after subcutaneous injections Somatuline $₫$ Autogel $\AA$ forms a depot with high concentrations of the drug within one day, followed by a controlled and prolonged release of the drug over a significant time [40]. Thus, in NET patients receiving a dose of $120 \mathrm{mg}$ of lanreotidedepot every four weeks, the plateau of drug concentration in the 
blood serum was reached after four or five injections with a level of 5.3 to $8.6 \mathrm{ng} / \mathrm{ml}$. Pharmacokinetic characteristics of lanreotide depot form allow using the drug at an interval of $4 \mathrm{w}$.

The depot form of lanreotide has other significant advantages: the preparation is ready to use; it is packed in a pre-filled device, which eliminates the need for a multi-stage process of solution preparation. Subcutaneous injections of the drug in small volume can be carried out by individuals without specialized medical training.

Also, the new design of the lanreotide syringe for injection provides an additional safety guarantee. It has a protective device that automatically retracts and blocks the needle after use, thus preventing from accidental puncture after injection. The syringe is transparent, and after full release of content, a click occurs, which allows controlling the administration of the drug. That is, the use of Somatuline ${ }^{\circledR}$ Autogel $₫$ allows achieving tumour control without impairing the quality of life of the patient [41-43].

\section{Pasireotide-SSA with universal binding profile}

It is well-known that SSAs exhibit direct antitumor activity through binding with SSTR, subtypes 1-5 expressed in neuroendocrine tumor cells [44]. Octreotide and lanreotide have an affinity to subtype two receptors (SSTR2), moderately bind to subtype five receptors (SSTR5), very weakly bind to SSTR3 and have little binding to SSTR1 and SSTR4 [45].

The concept of a metabolically stable SSA with the universal binding profile is realized in the cyclic hexapeptide-pasireotide (SOM 230, Signifor ${ }^{\circledR}$ ). Pasireotide has a high affinity to SSTR1, SSTR2, SSTR3 and SSTR5 receptors. Pasireotide affinity to SSTR1, SSTR3 and SSTR5 is 30, 11 and 158 times more top than that of Octreotide, respectively $[46,47]$.

Non-clinical investigations have shown that pasireotide inhibits the growth of NET in vitro significantly than octreotide [48]. Besides, the unique binding profile of pasireotide to receptors allows using it in patients with disseminated NET, refractory or resistant to octreotide/lanreotide. Pasireotide also can be used for the treatment of other tumours in which types SSTR2 and SSTR5 are relevant [49-51].

Initially, pasireotide dosage form contained $3 \mathrm{ml}$ of solution with an active substance concentration of $0.05 \mathrm{mg} / \mathrm{ml}$ or $1.0 \mathrm{mg} / \mathrm{ml}$ in vials. According to the results of phase I clinical trials, the dosage form of pasireotide was optimized. The drug registered in the USA, EU and Russia (Signifor ${ }^{\circledR}$, Novartis Pharma AG, Switzerland) is a solution of pasireotide diaspartate for injection with a concentration of $0.3 \mathrm{mg} / \mathrm{ml}, 0.6 \mathrm{mg} / \mathrm{ml}$ or $0.9 \mathrm{mg} / \mathrm{ml}$ in $1 \mathrm{ml}$ glass ampoules. In addition to the active substance, the drug contains mannitol as a regulator of the tonicity of the solution, tartaric acid as a buffering agent, sodium hydroxide to regulate $\mathrm{pH}$ and water for injection as a solvent. The product is recommended for subcutaneous administration twice a day.

Pasireotide prolonged-release dosage form (Signifor® LAR, Novartis Pharma AG, Switzerland) is a powder for suspension for injection in a vial that should be suspended in the supplied solvent immediately before application. The active substance of Signifor ${ }^{\circledR}$ LAR is pasireotide pamoate (or embonate). Unlike pasireotide diaspartate, it is practically insoluble in water and buffer solutions with a $\mathrm{pH}$ below 4.0 and demonstrates high stability in the selected controlledrelease polymer system. In the prolonged-release dosage form, pasireotide pamoate $(10,20 \mathrm{mg}, 30,40 \mathrm{mg}$ or $60 \mathrm{mg})$ is evenly distributed among biodegradable microspheres based on poly-D, Llactide-co-glycolide (PLGA). Both copolymers belong to the wellknown family of biocompatible poly (D, L-lactide-co-glycolide) copolymers, which are used for many years in similar commercial drugs [52-54]. They consist of lactide and glycolide, which are forming blocks, and degraded to lactic and glycolic acids, physiological to the body and metabolized by normal physiological pathways, and suitable for use in humans for parenteral administration. The active substance is gradually released from microspheres, primarily through diffusion and hydrolysis/ degradation. It is assumed that with the slow pasireotide release from the dosage form, its concentration will not fluctuate significantly, which will allow minimizing side effects. During non- clinical researches and phase I clinical trials different variants of copolymers compositions, their ratio and manufacturing processes were developed and tested. The proposed formulation has been chosen as having the most favorable pharmacokinetic profile [55].

The drug is packed in a blister containing pasireotide in the ampule and a solvent filled syringe, and adapter for the vial and a special needle for safe injection. The solvent consists of sodium carmellose, mannitol, poloxamer 188 and water for injection. It looks like a transparent solution of light yellow or light brown colour. The decision of solvent (selection of excipients, manufacturing process and choice of container closure system) is based on Novartis Pharma AG's previous experience in the development of medicines in microspheres [56].

Signifor ${ }^{\circledR}$ LAR is administered intramuscularly once every $28 \mathrm{~d}$. Clinical trials have shown that the use of pasireotide prolongedrelease dosage form allows achieving better control over the disease vs standard SSAs therapy-Sandostatin ${ }^{\circledR}$ LAR and Somatuline ${ }^{\circledR}$ Autogel ${ }^{\circledR}[57]$.

\section{Vapreotide}

Vapreotide (Octastatin ${ }^{\circledR}$, Sanvar ${ }^{\circledR}$, RC 160, BMY 41606) is a synthetic cyclic octapeptide, developed in Tulane University School of Medicine, USA [58]. Vapreotide exhibits an affinity to SSTR2 receptors and a lesser extent to SSTR5. As for other SSAs, the direct and indirect effect of vapreotide is manifested through the inhibition of release of the somatotropic hormone and other peptides. According to the non-clinical studies and clinical trials data, vapreotide has higher metabolic stability compared to other known SAS-it is the only SSA that remains stable for an extended time at room temperature. The therapeutic potential of vapreotide, however, is limited due to a short half-life.

Vapreotide is usually administered subcutaneously in the immediaterelease dosage form. A prolonged-release dosage form for intramuscular administration is also available. Other prolonged-release dosage forms are in the pharmaceutical development stage [59]. Sanvar® (H3 Pharma Inc., Canada), slow-release product (600 $\mathrm{gg}$ of vapreotide) has demonstrated statistically significant benefits of early use in clinical trials in the treatment of acute oesophagal variceal bleeding. Currently, phase III clinical trials are ongoing [60].

\section{SSAs dosage forms for oral administration}

The information provided above indicates that SSAs are manufactured in dosage forms for parenteral use for intramuscular/subcutaneous administration. Physical and chemical properties of active substances (large size of molecules, the tendency to aggregation, adsorption and denaturation) limit the development and application of dosage forms for oral use [61, 62]. Also, oral use of SSAs as peptides is characterized by low and variable systemic bioavailability due to the possibility of enzymatic decomposition in the gastrointestinal tract, inability to cross the epithelial barrier of the small intestine and short half-life time in blood plasma [63, 64].

Researchers from different countries have repeatedly made attempts to increase intestinal absorption of octreotide to create its oral dosage form, but none of them was commercially successful [65-67].

However, recently, Chiasma, Inc., USA, developed a new dosage form of octreotide $\left(\operatorname{Octreolin}^{\mathrm{TM}}\right.$ ), which is octreotide acetate in capsules for oral use. An innovative patented technology called Transient Permeability Enhancer (TPE®) is used for the manufacture of the drug product. It facilitates the gastrointestinal absorption of unmodified octreotide into the bloodstream. The dosage form manufactured by this technology is gastro-resistant capsules filled with a water-in-oil suspension of drug and sodium caprylate in hydrophilic microparticles, which are placed into lipophilic medium to increase intestinal permeability [68]. The drug creators claim that the $\mathrm{TPE}^{\circledR}$ system (primarily sodium caprylate) increases the bioavailability of octreotide after oral administration inducing the temporary and reversible opening of jejunal epithelial tight junctions. Improved paracellular absorption of the peptide through 
the wall of the small intestine provides its active entry into the systemic bloodstream in the unchanged native active form. On the other hand, TPE ${ }^{\circledR}$ technology protects the drug molecule from the aggressive effects of the gastrointestinal environment. In nonclinical studies, it was shown that intestinal absorption of octreotide is dose-dependent, and drug effect on the somatotropin hormone is comparable to the action of the injectable form of octreotide [69].

Phase I clinical trials demonstrated safety and satisfactory tolerability of the drug and the absence of severe side effects. It was shown that pharmacokinetic profiles of the drug are identical after single oral and subcutaneous injection [70]. Phase III clinical trial of Octreolin $^{\mathrm{TM}}$ conducted by Chiasma together with Roche (Switzerland) demonstrated the efficacy of the drug in control the activity of insulin-like growth factor and somatotropic hormone in patients transferred from registered injectable SSAs. The studies showed that Octreolin ${ }^{\mathrm{TM}}$ safety profile does not differ from that of the approved injectable SSAs. However, the study noted the effect of food products on the efficacy of the drug. Also, drug interactions were observed: the use of Octreolin ${ }^{\mathrm{TM}}$ capsules after meals or with proton pump inhibitors, such as esomeprazole, led to the changes of gastric $\mathrm{pH}$, significantly affecting oral absorption of the peptide [71].

Aegis Therapeutics LLC, USA, also attempted to create a dosage form of octreotide for oral use. E. Maggio and P. Grasso studied the bioavailability of octreotide acetate dissolved in Intravail ${ }^{\circledR}$ (a registered alkyl saccharide, a compound that improves transmucosal absorption). The results of a comparative pharmacokinetic study showed that oral administration of this dosage form is sufficient. It significantly increases total absorption $(1254.08 \mathrm{ng} / \mathrm{ml} / \mathrm{min}$ vs $311.63 \mathrm{ng} / \mathrm{ml} / \mathrm{min}$, respectively), bioavailability ( $4.0 \mathrm{vs} 1.0$ ) and serum half-life ( $52.1 \mathrm{~min}$ vs $1.3 \mathrm{~min}$ ), as compared to subcutaneous administration. Thus, oral administration of octreotide in the form of Intravail $@$ is a new practical approach for non-invasive treatment of NET [72].

\section{Cyphetrylin-SSA, worked out in Russia}

At the N. N. Blokhin National Medical Research Center of Oncology investigators worked on the synthesis of SSAs (including cytotoxic) for many years, and also the investigation of antitumour activity of the obtained compounds was carried out [73, 74].

Cyphetrylin, which is a noncyclic pentapeptide, SSA, showed a pronounced antitumour activity in vitro and in vivo [75]. Due to the protection of the reactive side-chain groups with tretbutyloxycarbonylic, benzyloxycarbonylic and tetrahydropyran groups, Cyphetrylin is metabolically resistant in the acidic environment of the stomach which allows developing a dosage form of the drug for oral use [76, 77].

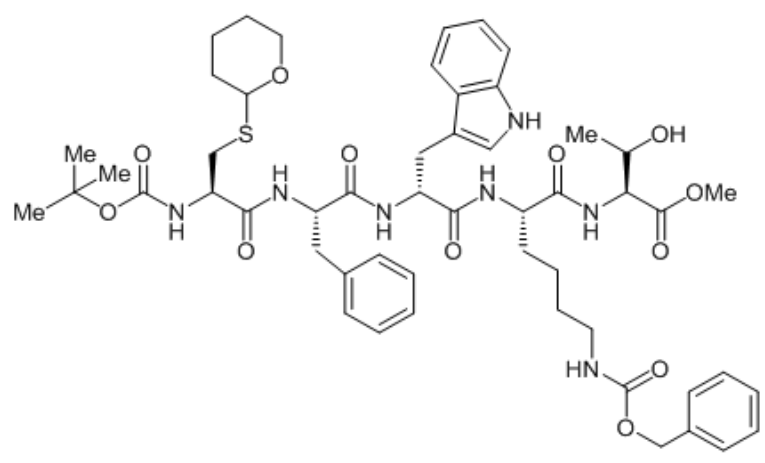

Fig. 1: Structural formula of Cyphetrylin

Non-clinical studies of Cyphetrylin dosage form models showed that oral administration allows maximizing its antitumour effect: the drug inhibits the growth of experimental tumours by $83-90 \%$ with a statistically significant therapeutic effect during three weeks [78]. Non-clinical studies of Cyphetrylin tablets pharmacokinetics showed the availability of Cyphetrylin for all studied organs and tissues, including brain and tumour [79]. And the results of non-clinical safety studies allowed to determine the initial (starting) safe dose for humans for phase I clinical trials [80].

\section{CONCLUSION}

SSAs play an essential role in drug therapy of NET. It follows from the above that the researches in this group of medicines are focused on prolonged therapeutic effect of drugs to reduce the number of administration. The development of dosage forms for oral administration makes it possible to proceed to non-invasive treatment of NET. Thus, achievements in the development of innovative dosage forms of SSAs not only significantly simplify the therapy of patients with NET, but dramatically increase the quality of life of such patients.

\section{ACKNOWLEDGMENT}

This work was funded by Russian Ministry of Industry and Trade (Grant Number 11411.0008700.13.082).

\section{AUTHORS CONTRIBUTIONS}

All the author have contributed equally.

\section{CONFLICT OF INTERESTS}

Declared none

\section{REFERENCES}

1. Fraenkel M, Fagiano A, Valk GD. Epidemiology of neuroendocrine tumors. Front Horm Res 2015;44:1-23.

2. Jimenez Fonseca P, Carmona Bayonas A, Martin Perez E, Crespo G, Serrano R, Llanos M, et al. Health-related quality of life in welldifferentiated metastatic gastroenteropancreatic neuroendocrine tumors. Cancer Metastasis Rev 2015;3:381-400.

3. Chalabi M, Duluc C, Caron P, Vezzosi D, Guillermet Guibert J, Pyronnet St, et al. Somatostatin analogs: does pharmacology impact antitumor efficacy? Trends Endocrinol Metab 2014;3:115-27.

4. Narayanan S, Kunz PL. Role of somatostatin analogues in the treatment of neuroendocrine tumors. Hematol Oncol Clin North Am 2016;1:163-77.

5. Mazziotti G, Mosca A, Frara S, Vitale G, Giustina A. Somatostatin analogs in the treatment of neuroendocrine tumors: current and emerging aspects. Expert Opin Pharmacother 2017;16:1679-89.

6. Grozinsky Glasberg S, Shimon I, Korbonits M, Grossman AB. Somatostatin analogues in the control of neuroendocrine tumours: efficacy and mechanisms. Endocr Relat Cancer 2008;3:701-20.

7. Anthony L, Freda PU. From somatostatin to octreotide LAR: evolution of a somatostatin analogue. Curr Med Res Opin 2009;12:2989-99.

8. Katznelson L, Atkinson JL, Cook DM, Ezzat SZ, Hamrahian AH, Miller KK. American association of clinical endocrinologists medical guidelines for clinical practice for the diagnosis and treatment of acromegaly-2011 update executive summary. Endocr Pract 2011;17 Suppl 4:1-44. 
9. Patel D, Chan D, Cenic G, Pavlakis N, Proce TJ. Systemic therapies for advanced gastroenteropancreatic neuroendocrine tumors. Expert Rev Endocrinol Metab 2016;4:311-27.

10. Kunz PL, Reidy Lagunes D, Anthony LB, Bertino EM, Brendtro $\mathrm{K}$, Chan JA, et al. Consensus guidelines for the management and treatment of neuroendocrine tumors. Pancreas 2013;4:557-77.

11. Oberg KE. The management of neuroendocrine tumours: current and future medical therapy options. Clin Oncol 2012;4:282-93.

12. Rai U, Thrimawithana TR, Valery C, Young SA. Therapeutic uses of somatostatin and its analogues: current view and potential applications. Pharmacol Ther 2015;152:98-110.

13. Bousquet C, Lasfargues C, Chalabi M, Billah SM, Susini C, Vezzosi D, et al. Current scientific rationale for the use of somatostatin analogs and mTOR inhibitors in neuroendocrine tumor therapy. J Clin Endocrinol Metab 2012;3:727-37.

14. Massironi S, Zilli A, Conte D. Somatostatin analogs for gastric carcinoids: for many, but not all. World J Gastroenterol 2015;22:6785-93.

15. Mohammed GK, Obaidat RM, Assaf S, Khanfar M, Al-taani B. Formulations and technologies in growth hormone delivery. Int J Pharm Pharm 2017;7:1-12.

16. Wolin EM. The expanding role of somatostatin analogs in the management of neuroendocrine tumors. Gastrointest Cancer Res 2012;5:161-8.

17. Crabtree JS. Clinical and preclinical advances in gastroenteropancreatic neuroendocrine tumor therapy. Front Endocrinol 2017;8:341.

18. Ruscica M, Arvigo M, Steffani L, Ferone D, Magni P. Somatostatin, somatostatin analogs and somatostatin receptor dynamics in the biology of cancer progression. Curr Mol Med 2013;4:555-71.

19. Rubin J, Ajani J, Schirmer W, Venook AP, Bukowski R, Pommier $\mathrm{R}$, et al. Octreotide acetate long-acting formulation versus open-label subcutaneous octreotide acetate in malignant carcinoid syndrome. J Clin Oncol 1999;2:600-6.

20. Tiberg F, Johnsson M, Jankunec M, Barauskas J. Phase behavior, functions, and medical applications of soy phosphatidylcholine and diglyceride lipid compositions. Chem Lett 2012;10:1090-2.

21. Tiberg F, Johnsson M. Drug delivery applications of nonlamellar liquid crystalline phases and nanoparticles. J Drug Delivery Sci Technol 2011;1:101-9.

22. Tiberg F, Roberts J, Cervin C, Johnsson M, Sarp S, Tripanti AP, et al. Octreotide s. c. depot provides sustained octreotide bioavailability and similar IGF-1 suppression to octreotide LAR in healthy volunteers. Br J Clin Pharmacol 2015;3:460-72.

23. Tekade RK. editor. Biomaterials and bionanotechnology (Advances in pharmaceutical product. Development and research series) 1st ed. Ahmedabad: Academic Press (Elsevier); 2019.

24. Chieffo C, Cook D, Xiang Q, Frohman LA. Efficacy and safety of an octreotide implant in the treatment of patients with acromegaly. J Clin Endocrinol Metab 2013;10:4047-54.

25. Gadelha MR, Chieffo C, Bai SA, Hu X, Frohman LA. A subcutaneous octreotide hydrogel implant for the treatment of acromegaly. Endocr Pract 2012;6:870-81.

26. Hofland LJ, Van der Hoek J, Feelders R, van der Lely AJ, de Herder W, Lamberts SW. Pre-clinical and clinical experiences with novel somatostatin ligands: advantages, disadvantages and new prospects. J Endocrinol Invest 2005;28(11 Suppl):36-42.

27. Lombardi G, Minuto F, Tamburrano G, Ambrosio MR, Arnaldi G, Arosio $\mathrm{M}$, et al. Efficacy of the new long-acting formulation of lanreotide (lanreotide Autogel) in somatostatin analog-naive patients with acromegaly. J Endocrinol Invest 2009;3:297-303.

28. Siepmann J, Faisant N, Akiki J, Richard J, Benoit JP. Effect of the size of biodegradable microparticles on drug release: experiment and theory. J Controlled Release 2004;1:123-34.

29. Estey T, Kang J, Schwendeman SP, Carpenter JF. BSA degradation under acidic conditions: a model for protein instability during release from PLGA delivery systems. J Pharm Sci 2006; 7:1626-39.

30. Lewis AL, Illum L. Formulation strategies for sustained release of proteins. Ther Delivery 2010;3:457-79.

31. Gobeaux F, Fay N, Tarabout C, Meriadec C, Meneau F, Ligeti M, et al. Structural role of counterions adsorbed on self-assembled peptide nanotubes. J Am Chem Soc 2012;1:723-33.
32. Gobeaux F, Fay N, Tarabout C, Meneau F, Meriadec C, Delvaux $\mathrm{C}$, et al. Experimental observation of double-walled peptide nanotubes and monodispersity modeling of the number of walls. Langmuir 2013;8:2739-45.

33. Pandit A, Fay N, Bordes L, Valery C, Cherif Cheikh R, Robert B, et al. Self-assembly of the octapeptide lanreotide and lanreotide-based derivatives: the role of the aromatic residues. J Pept Sci 2008;1:66-75.

34. Pouget E, Dujardin E, Cavalier A, Moreac A, Valery C, Marchi Artzner $\mathrm{V}$, et al. Hierarchical architectures by the synergy between dynamical template self-assembly and biomineralization. Nat Mater 2007;6:434-9.

35. Pouget E, Fay N, Dujardin E, Jamin N, Berthault P, Perrin L, et al. Elucidation of the self-assembly pathway of lanreotide octapeptide into beta-sheet nanotubes: role of two stable intermediates. J Am Chem Soc 2010;12:4230-41.

36. Valery C, Artzner F, Robert B, Gulick T, Keller G, Grabielle Madelmont C, et al. Self-association process of a peptide in solution: from beta-sheet filaments to large embedded nanotubes. Biophys J 2004;4:2484-501.

37. Valery C, Pouget E, Pandit A, Verbavatz JM, Bordes L, Boisde I, et al. Molecular origin of the self-assembly of lanreotide into nanotubes: a mutational approach. Biophys J 2008;5:1782-95.

38. Gobeaux F, Fay N, Tarabout C, Meriadec C, Meneau F, Ligeti M, et al. Structural role of counterions adsorbed on self-assembled peptide nanotubes. J Am Chem Soc 2012;1:723-33.

39. Troconiz IF, Cendros JM, Peraire C, Ramis J, Garrido MJ, Boscani $\mathrm{PF}$, et al. Population pharmacokinetic analysis of lanreotide autogel in healthy subjects: evidence for injection interval of up to 2 mo. Clin Pharmacokinet 2009;1:51-62.

40. Buil Bruna N, Garrido M, Dehez M, Manon A, Nguyen THQ, Gomez Panzani El, et al. Population pharmacokinetic analysis of lanreotide autogel (囚)/Depot in the treatment of neuroendocrine tumors: pooled analysis of four clinical trials. Clin Pharmacokinet 2016;4:461-73.

41. Adelman DT, Burgess A, Davies PR. Evaluation of long-acting somatostatin analog injection devices by nurses: a quantitative study. Med Devices (Auckl) 2012;5:103-9.

42. Witek P, Mucha S, Ruchata M. Patient satisfaction and preferences of lanreotide autogel treatment in acromegaly. Endokrynol Pol 2016;6:572-9.

43. Wolin EM, Manon A, Chassaing C, Lewis A, Bertocchi L, Richard $\mathrm{J}$, et al. Lanreotide depot: an antineoplastic treatment of carcinoid or neuroendocrine tumors. J Gastrointest Cancer 2016;4:366-74.

44. Susini C, Buscail L. Rationale for the use of somatostatin analogs as antitumor agents. Ann Oncol 2006;12:1733-42.

45. Oberg K, Kvols LK, Caplin M, Delle Fave G, de Herder W, Rindi $\mathrm{G}$, et al. Consensus report on the use of somatostatin analogs for the management of neuroendocrine tumors of the gastroenteropancreatic system. Ann Oncol 2004;6:966-73.

46. Bruns C, Lewis I, Briner U, Meno Tetang G, Weckbecker G. SOM230: a novel somatostatin peptidomimetic with broad somatotropin release inhibiting factor (SRIF) receptor binding and a unique antisecretory profile. Eur J Endocrinol 2002;5:707-16.

47. Schmid HA. Pasireotide (SOM230): development, mechanism of action and potential applications. Mol Cell Endocrinol 2008;12:69-74.

48. Golor G, Hu K, Ruffin M, Buchelt A, Bouillaud E, Wang Y, et al. A first-in-man study to evaluate the safety, tolerability, and pharmacokinetics of pasireotide (SOM230), a multireceptortargeted somatostatin analog, in healthy volunteers. Drug Des Dev Ther 2012;6:71-9.

49. Petersenn S, Schopohl J, Barkan A, Mohideen P, Colao A, Abs R, et al. Pasireotide (SOM230) demonstrates efficacy and safety in patients with acromegaly: a randomized, multicenter, phase II trial. J Clin Endocrinol Metab 2010;6:2781-9.

50. Feelders RA, de Bruin C, Pereira AM, Romijn JA, Netea Maier RT, Hermus AR, et al. Pasireotide alone or with cabergoline and ketoconazole in cushing's disease. N Engl J Med 2010;19:1846-8.

51. Boscaro M, Ludlam WH, Atkinson B, Glusman JE, Petersenn S, Reincke $\mathrm{M}$, et al. Treatment of pituitary-dependent cushing's disease with the multireceptor ligand somatostatin analog 
pasireotide (SOM230): a multicenter, phase II trial. J Clin Endocrinol Metab 2009;1:115-22.

52. Kohli S, Pal A, Jain S. Preparation, characterization and evaluation of poly(lactide-co-glycolide) microspheres for the controlled release of zidovudine. Int J Pharm Pharm 2017;12:70-7.

53. Settu K, Vaiyapuri M. Formulation and evaluation of isorhamnetin loaded poly lactic-co-glycolic acid nanoparticles. Asian J Pharm Clin Res 2017;11:177-81.

54. El-feky GS, Zayed GM. PLGA nanoparticles loaded mucoadhesive and termosensitive hydrogel as potential platform for the treatment of oral mucositis. Int J Appl Pharm 2019;1:106-12.

55. Mishra R, Mir SR, Amin S. Polymeric nanoparticles for improved bioavailability of cilnidipine. Int J Pharm Pharm 2017;4:129-33.

56. Cuevas Ramos D, Fleseriu M. Pasireotide: a novel treatment for patients with acromegaly. Drug Des Dev Ther 2016;10:227-39.

57. Kvols LK, Oberg KE, O’Dorisio TM, Mohideen P, De Herder WW, Arnold R, et al. Pasireotide (SOM230) shows efficacy and tolerability in the treatment of patients with advanced neuroendocrine tumors refractory or resistant to octreotide LAR: results from a phase II study. Endocr Relat Cancer 2012;5:657-66.

58. Norman P. Vapreotide (Debipharm). I Drugs 2000;11:1358-72.

59. Dasgupta P, Mukherjee R. Lipophilization of somatostatin analog RC-160 with long chain fatty acid improves its antiproliferative and antiangiogenic activity in vitro. $\mathrm{Br} \mathrm{J}$ Pharmacol 2000;1:101-9.

60. Vapreotide (BMY 41606, RC 160, Sanvar®). Drugs in R and D 2003;5:326-30

61. Shaji J, Patole V. Protein and peptide drug delivery: oral approaches. Indian J Pharm Sci 2008;3:269-77.

62. Bak A, Leung D, Barrett SE, Forster S, Minnihan EC, Leithead $\mathrm{AW}$, et al. Physicochemical and formulation developability assessment for therapeutic peptide delivery-a primer. AAPS J 2015;1:144-55

63. Thundimadathil J. Cancer treatment using peptides: current therapies and future prospects. J Amino Acids 2012. Doi:10.1155/2012/967347

64. Preet P. Peptides: a new therapeutic approach. Int J Curr Pharm Res 2018;2:29-34.

65. Dorkoosh FA, Verhoef JC, Verheijden JH, Rafiee Tehrani M, Borchard G, Junginger HE. Peroral absorption of octreotide in pigs formulated in delivery systems on the basis of superporous hydrogel polymers. Pharm Res 2002;10:1532-6.

66. Thanou M, Verhoef JC, Marbach P, Junginger HE. Intestinal absorption of octreotide: $\mathrm{N}$-trimethyl chitosan chloride (TMC) ameliorates the permeability and absorption properties of the somatostatin analogue in vitro and in vivo. J Pharm Sci 2000;7:951-7.
67. Thanou M, Verhoef JC, Verheijden JH, Junginger HE. Intestinal absorption of octreotide using trimethyl chitosan chloride: studies in pigs. Pharm Res 2001;6:823-8.

68. McCartney F, Gleeson JP, David J, Brayden DJ. Safety concerns over the use of intestinal permeation enhancers: a mini-review. Tissue Barriers 2016;2:e1176822.

69. Tuvia S, Salama P, Weinstein I, Marom K, Neumark E, Arama $\mathrm{ML}$, et al. Octreolin a safe oral alternative for parenteral octreotide treatment. Growth Horm IGF Res 2010;20 Suppl 1:835-6.

70. Tuvia S, Atsmon J, Teichman SL, Katz S, Salama P, Pelled D, et al. Oral octreotide absorption in human subjects: comparable pharmacokinetics to parenteral octreotide and effective growth hormone suppression. J Clin Endocrinol Metab 2012;7:2362-9.

71. Melmed S, Popovic V, Bidlingmaier M, Mercado M, Van Der Lely $\mathrm{AJ}$, Biermasz N, et al. Safety and efficacy of oral octreotide in acromegaly: results of a multicenter phase III trial. J Clin Endocrinol Metab 2015;4:1699-708.

72. Maggio ET, Grasso P. Oral delivery of octreotide acetate in Intravail $\AA$ improves uptake, half-life, and bioavailability over subcutaneous administration in male swiss webster mice. Regul Pept 2011;2-3:233-8.

73. Osipov VN, Sushinina LP, Ustinkina SV, Smirnova LI, Shprakh ZS. Cyphetrylin cytotoxic analogues (report I). Russ J Biother 2016;4:85-8.

74. Borisova LM, Kiseleva MP, Osipov VN, Sushinina LP, Ustinkina $\mathrm{SV}$, Smirnova LI, et al. Cyphetrylin cytotoxic analogues (report II). Russ J Biother 2017;2:23-9.

75. Shprakh ZS, Yartseva IV, Ignateva EV, Smirnova AP, Sushinina LP, Ustinkina SV, et al. Synthesis and chemico-pharmaceutical characteristics of somatostatin analog with antitumor activity. Pharm Chem J 2014;3:159-62.

76. Mikhaevich EI, Yavorskaya NP, Golubeva IS, Polozkova AP, Partolina SA, Oborotova NA. Studying the possibility of oral delivery of cyphetrylin. Russ J Biother 2012;1:3-7.

77. Shprakh ZS, Ignatieva EV, Yartseva IV, Dmitricheva NA Smirnova LI. Development and validation of cyphetrylin assay in tablets. Russ J Biother 2016;3:55-61.

78. Shprakh ZS, Borisova LM, Kiseleva MP, Smirnova ZS. Preclinical study of cyphetrylin antitumor efficiency on experimental animal tumors. Exp Clin Pharmacol 2019;8:27-31.

79. Zimakova NI, Kolesnikova EY, Budko AP, Deychman ZG, Zolotarev AE, Badun GA, et al. Preclinical study pharmacokinetics drug form of analog hypothalamic hormone somatostatine (AGG). Russ J Biother 2012;3:33-8.

80. Konyaeva OI, Kulbachevskaya NYu, Ermakova NP, Chaley VA, Merkulova IB, Abramova TV, et al. Pre-clinical toxicological study of analogue of hypothalamic hormone. Russ J Biother 2018;2:63-70. 